\title{
Evaluation of serum-based real-time PCR to detect Schistosoma mansoni infection before and after treatment
}

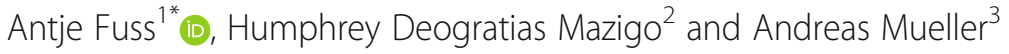

\begin{abstract}
Background: To detect acute schistosomiasis, low-intensity infections, or to verify the success of treatment with praziquantel, highly sensitive test methods are required. The aim of this study was therefore to demonstrate the performance of Schistosoma mansoni specific DNA detection in serum and urine using real-time polymerase chain reaction (PCR) in an endemic area before and after treatment.
\end{abstract}

Methods: The study pursued a 1-week and 20-weeks longitudinal design with a treatment intervention among 36 study participants aged 18 to 70 years in the community of Kayenze, a fishing village in llemela district on the southern shore of Lake Victoria in north-western Tanzania between February and June 2018. Blood, urine and stool samples were collected from each participant to diagnose Schistosoma mansoni infection before and two times after treatment with praziquantel using serum- and urine based real-time PCR, point-of-care circulating cathodic antigen (POC-CCA) rapid diagnostic test and the microscopic Kato-Katz (KK) method. Kappa coefficient (K) was used to estimate the agreement between these diagnostic tests compared to a combined "gold standard" of positive results by serum-based real-time PCR and/or positive egg counts determined by KK. Kendall's Tau rank correlation was used to examine the relationship between cycle threshold (Ct)-values and egg counts and the Wilcoxon signed-rank test was used to compare the median Ct-values of the different examination time points.

Results: By using the combined "gold standard" of the parasitological Kato-Katz test and/or serum-based real-time PCR, a S. mansoni prevalence of $77.1 \%$ could be determined at baseline. In terms of sensitivity, serum-based realtime PCR (96.3\%) and POC-CCA assay (77.8\%) showed the highest results. The detection of DNA from urine samples showed the lowest sensitivity (33.3\%). Treatment with praziquantel resulted in a significantly reduced prevalence of S. mansoni. No infection could be detected by Kato-Katz, with the POC-CCA test only 33.3\%. The analysis of the median Ct values over time (which were determined by the serum-based real-time PCR) showed that the Ct decreases significantly shortly after treatment (from 30.3 to 28) and increases above baseline level (34.9) three months later.

Conclusions: The data presented here show that the serum-based real-time PCR exhibits excellent diagnostic accuracy, in contrast to the use of urine as sample material for S. mansoni DNA detection. However, as circulating DNA does not necessarily reflect the persistence of living worms in schistosomiasis, this method is less well suited to verify the success of treatment with praziquantel.

Keywords: Schistosoma mansoni, Real-time PCR, Circulating DNA, Tanzania

\footnotetext{
* Correspondence: antje.fuss@medmissio.de

${ }^{1}$ Medical Mission Institute, Hermann-Schell-Str. 7, 97074 Wuerzburg, Germany

Full list of author information is available at the end of the article
}

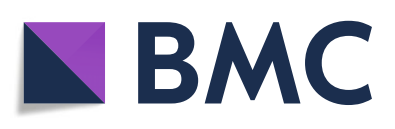

(c) The Author(s). 2020 Open Access This article is licensed under a Creative Commons Attribution 4.0 International License, which permits use, sharing, adaptation, distribution and reproduction in any medium or format, as long as you give appropriate credit to the original author(s) and the source, provide a link to the Creative Commons licence, and indicate if changes were made. The images or other third party material in this article are included in the article's Creative Commons licence, unless indicated otherwise in a credit line to the material. If material is not included in the article's Creative Commons licence and your intended use is not permitted by statutory regulation or exceeds the permitted use, you will need to obtain permission directly from the copyright holder. To view a copy of this licence, visit http://creativecommons.org/licenses/by/4.0/ The Creative Commons Public Domain Dedication waiver (http://creativecommons.org/publicdomain/zero/1.0/) applies to the data made available in this article, unless otherwise stated in a credit line to the data. 


\section{Background}

Human schistosomiasis is considered as one of the most prevalent parasitic infections in the world with an estimated 229 million people requiring preventive treatment [1]. In sub-Saharan Africa, Schistosoma mansoni is one of the major species causing hepatic and intestinal schistosomiasis [2, 3]. The Kato-Katz method (KK) for microscopic detection of $S$. mansoni eggs in stool and the urine rapid diagnostic test for detection of circulating cathodic antigens (CCA) are extensively used for screening of schistosomiasis [4]. The KK method is cheap, easy to use and offers high diagnostic specificity in endemic areas with high parasite burden. However, sensitivity is low when this test is used in non-endemic areas or for the diagnosis of infections at an early stage [5]. The point-of-care circulating cathodic antigen (POC-CCA) test is also easy to use and the utilization of urine samples instead of stool as sample material leads to an increased acceptance by patients and a very good applicability for epidemiological surveys in large populations [6]. In numerous studies, especially with regard to S. mansoni, the POC-CCA test has shown higher prevalence rates than the KK test [7, 8]. Nevertheless, even this test seems to have limited sensitivity in areas with low infection intensity [9]. Therefore, both the microscopic KK test and the POC-CCA test are limited in terms of therapy control and assessment of control programs [10]. False negative results are a major problem, especially in elimination programs, because a limited number of surviving cases can spread infections rapidly and may negate the success of control programs [11, 12]. In addition, highly sensitive tests are important to detect acute schistosomiasis [13], low-intensity and residual infections $[11,12]$. A suitable instrument for these applications could be molecular methods based on polymerase chain reaction (PCR) for the detection of parasite DNA. Parasitic cells or free-circulating parasitic DNA can be released from parasites into blood or urine and detected in these samples by PCR [14]. Thus, the use of stool samples, which often cannot be provided directly, can be avoided for the diagnosis of schistosomiasis [11]. The most desirable specimen is urine, as it is readily available, non-invasive, and can be easily collected in schools and clinics. However, patients are also often willing to provide a small amount of blood for examination [11]. Based on the frequently used sequence SM1-7, PCR [15], real-time PCR [16] and loop-mediated isothermal amplification (LAMP) [17] methods were established. SM1-7 is a highly repeated, tandemly arranged DNA sequence of S. mansoni, which contains $121 \mathrm{bp}$ tandem repeats and comprises at least $12 \%$ of $S$. mansoni genome of both sexes [18]. Specificity tests have shown that there are no cross reactions with other helminths [18]. Wichmann et al. described in 2009 the detection of cell-free S. mansoni DNA by real-time PCR in plasma also using this sequence [19]. Due to the negative correlation between the cycle threshold $(\mathrm{Ct}$ )-value (defined as the number of cycles required for the fluorescent signal to exceed the background level) and the number of target copies, the real-time PCR method also offers the advantage of a quantitative analysis [20]. Therefore, this method might be suitable not only for the initial diagnosis but also for follow-up monitoring. First promising results were obtained in a previous study on experimentally infected mice [19].

In this study we investigated whether the detection of circulating free DNA from urine and serum samples using real-time PCR is suitable for diagnosing schistosomiasis compared to $\mathrm{KK}$ and POC-CCA test. In addition, we investigated whether serum-based real-time PCR can be used to assess the therapeutic success of praziquantel (PZQ) in a high prevalence setting on Lake Victoria. For this purpose, serum $\mathrm{Ct}$ values were compared during infection and after therapy.

\section{Methods \\ Study area and population}

The study pursued a longitudinal design with a treatment intervention and was conducted between March and July 2018 in the community of Kayenze, a fishing village in Ilemela district on the southern shore of Lake Victoria in north-western Tanzania. The majority of the inhabitants depend on the lake for domestic and economic activities including fishing, farming, washing, bathing, cooking, drinking and recreation. The region is endemic for S. mansoni [21-23] and the high occupational exposure keeps the intensity of S. mansoni infection high in adulthood [24]. Annual mass drug administration (MDA) using PZQ against schistosomiasis and albendazole against soil-transmitted helminthiases in this village is school-based and targets schoolchildren, not adults [21]. The study included only adult participants (aged 18-70 years) who provided written informed consent and had no treatment with PZQ in the last 12 months.

\section{Sample collection}

Serum, urine and stool samples from adult participants with a proven $S$. mansoni infection were assessed during a baseline survey and again 1 week (6-8 days) and 20 weeks (142-144 days) after PZQ administration (40 mg/ $\mathrm{kg})$. These participants belonged to a larger group selected for a prevalence study. The cohort examined for the current study consisted of 36 participants, who had been present at all follow-up time points and of whom serum and urine samples were available for real-time PCR analyses. The stool sample of one study participant was missing at baseline data collection. Serum samples 
were obtained after centrifugation of coagulated blood samples at $1200 \times g$ for $5 \mathrm{~min}$. The supernatant was centrifuged for further $15 \mathrm{~min}$ at $3000 \times g$ and then stored frozen at $-20{ }^{\circ} \mathrm{C}$. The centrifugation steps were performed at room temperature. Aliquots of urine $(15 \mathrm{ml})$ were preserved with Norgen ${ }^{\circ}$ Urine Preservative (Thorold, Canada) for nucleic acid extraction and stored at room temperature until use.

\section{Microscopic examination}

Stool samples were evaluated for the presence of $S$. mansoni eggs by the quantitative Kato Katz (KK) thick smear technique. For the KK method two thick smears were prepared from different parts of a single stool sample using a template of $41.7 \mathrm{mg}$ (Vestergaard Frandsen, Lausanne, Switzerland), following a standard protocol [25, 26]. After $24 \mathrm{~h}$, the smears were independently examined for $S$. mansoni eggs by two experienced laboratory technicians of the National Institute for Medical Research (NIMR). For quality assurance, $10 \%$ of the negative and positive KK thick smears were re-examined by a third laboratory technician.

\section{POC-CCA urine rapid diagnostic test}

Urine samples were tested for CCA of Schistosoma by the POC-CCA cassette test according to the protocol and procedures described by the manufacturer (Rapid Diagnostics, Pretoria, South Africa). Trace readings were considered as positive test results.

\section{DNA extraction from serum and urine samples}

DNA extraction from $2 \mathrm{ml}$ serum and $4 \mathrm{ml}$ preserved urine were performed using the QIAamp Circulating Nucleic Acid Kit according to the manufacturer's suggestions (Qiagen, Hilden, Germany). DNA was stored at $-20^{\circ} \mathrm{C}$ after extraction.

\section{Amplification by real-time PCR}

Detection of cell-free S. mansoni DNA samples was performed according to a previously published protocol [19] using a set of primers and probes complementary to a $121 \mathrm{bp}$ tandem repeat sequence of $S$. mansoni strain SM 1-7 (GenBank accession number M61098) described by Hamburger et al. [18]. Primer sequences were: Sm FW 5'-CCG ACC AAC CGT TCT ATG A-3'; Sm RV 5'CAC GC TCT CG C AAA TAA TCT AAA-3'; Sm probe $5^{\prime}$-[FAM] TCG TTG TAT CTC CGA AAC CAC TGG ACG [(BHQ1])-3' all synthesized by Eurofins Genomics, Ebersberg, Germany.

The $25 \mu$ l reaction mix contained $2.5 \mu \mathrm{l}$ DNA, $1 \mathrm{x}$ QuantiFast Pathogen Master Mix (QuantiFast ${ }^{\circ}$ Pathogen PCR + IC Kit, Qiagen, Hilden, Germany), $400 \mathrm{nmol} / \mathrm{L}$ of each $\mathrm{Sm}$ Primer and $200 \mathrm{nmol} / \mathrm{L}$ of $\mathrm{Sm}$ probe. The PCR runs consisted of an initial step of $5 \mathrm{~min}$ at $95^{\circ} \mathrm{C}$ followed by 40 successive cycles of $15 \mathrm{~s}$ at $95^{\circ} \mathrm{C}$ and $30 \mathrm{~s}$ at $60^{\circ} \mathrm{C}$. The reaction was run on the StepOne real-time PCR system (Applied Biosystems). DNA detection was expressed by $\mathrm{Ct}$ - values. In every run, the non-template control was negative $(\mathrm{Ct}=0)$, the positive control $(S$. mansoni egg DNA) was positive and the exogenous Qiagen Internal Control to test successful amplification and to exclude the presence of PCR inhibitors was positive $(\mathrm{Ct}<33)$ (The QuantiFast Pathogen PCR + IC Kit provides a ready-to-use Internal Control for universal use). A test was considered positive when the threshold was attained within 40 PCR cycles $(\mathrm{Ct}<40)$.

\section{Statistical analyses}

Statistical analysis were carried out using IBM SPSS Statistics version 24 (SPSS Inc., Chicago, USA) and Microsoft Excel 2013 (Microsoft Corporation, Redmond, USA). A $P$-value lower than 0.05 was considered statistically significant.

The prevalence of $S$. mansoni was determined for each diagnostic method and mean values (with 95\% confidence intervals $[\mathrm{CI}]$ ) and medians were calculated for the Ct-values and eggs per gram stool (EPG). This study used a combined diagnostic "gold standard" of positive results by serum-based real-time PCR and/or positive egg counts as determined by KK. A combined "gold standard" is used to obtain a reliable result and has been described in other studies [27]. Since this approach assumes a specificity of $100 \%$ for both test methods, only sensitivity and negative predicted value (NPV) were calculated for all assays used at baseline. Diagnostic results were converted to binary variables $(1=$ positive and $0=$ negative). Kappa coefficient ( $\mathrm{\kappa}$ ) was used to statistically estimate the agreement between one diagnostic tool compared to the "gold standard".

By using the real-time PCR method, the Ct-value is displayed. The $\mathrm{Ct}$ is defined as the number of cycles required for the fluorescent signal to cross the threshold (i.e. exceeds background level). Ct levels are inversely proportional to the amount of target nucleic acid in the sample (the lower the Ct level the greater the amount of target nucleic acid in the sample). The relationship between Ct-values and egg counts was examined by the Kendall's Tau rank correlation ( $\mathrm{\tau})$. A nonparametric test (Wilcoxon signed-rank test) was used to compare the median Ct-values of the different examination time points.

\section{Results}

\section{Demographic information of study participants}

Study participants who provided sample material for the current study consisted of 28 females (77.8\%) and 8 males with a mean age of 34 years (range: 18 to 70 years). 


\section{Baseline prevalence}

Based on KK technique, the overall prevalence of $S$. mansoni was 34.3\%. Egg loads varied between 12 and 1284 EPG with a median of 120 EPG. Real-time PCR detected S. mansoni DNA in 27 (75.0\%) of serum samples with Ct-values ranging between 22.6 and 38 and a median Ct-value of 30.3. In urine, real-time PCR yielded $30.6 \%$ S. mansoni positive samples with Ct values between 33.9 and 40 and a median Ct-value of 38.5. The prevalence determined with the commercially available POC-CCA rapid test was $63.9 \%$ (Table 1 ).

\section{Assessment of the different diagnostic tools using a combined "gold standard"}

The "gold standard" used was a combination of the parasitological KK test and/or real-time PCR of serum samples. According to this procedure, $77.1 \%$ (27/35) $S$. mansoni positive samples were determined. Due to a missing stool sample, only the results of 35 study participants could be included in the combined standard. The KK method showed a sensitivity of $44.4 \%$ with a negative predicted value (NPV) of 34.8\%. Kappa agreement between the microscopy and the defined standard was poor $(\mathrm{k}=0.268, P=0.02)$. The POC-CCA test had a higher sensitivity $(77.8 \%)$ and NPV (53.9\%) than the KK test. The Kappa statistic was $0.535(P<0.001)$. Serumbased real-time PCR displayed the highest sensitivity (96.3\%) and NPV (88.9\%), as well as high Kappa agreement $(\mathrm{k}=0.922, P<0.001)$. This technique missed one out of 27 positive cases. The lowest sensitivity (33.3\%) and NPV (28\%) was achieved by the method of urinebased real-time PCR. The Kappa agreement between this test and the "gold standard" was $0.119(P=0.25)$. These results are summarized in Table 2 . Due to the low performance of the urine-based real-time PCR, this method was not included in post-treatment examinations.

\section{Post-treatment prevalence and intensity of S. mansoni infection}

Treatment with PZQ resulted in a significantly reduced prevalence of $S$. mansoni after 20 weeks. Using the KK method, no infection could be detected (0\%). The POC-
CCA test detected 33.3\% (12/36), the serum-based realtime PCR 58.3\% S. mansoni positive samples (Table 3).

\section{PCR polymerase chain reaction; POC-CCA point-of-care circulating cathodic antigen}

Accordingly, serum-based real-time PCR showed the highest proportion of $S$. mansoni positives both at baseline and at 20 weeks after treatment. Examination of the median Ct-values, which are inversely proportional to the level of DNA, showed a median Ct value of 30.3 at baseline, which decreased significantly to 287 days after treatment $(\mathrm{z}=-2.395, P=0.017)$. Twenty weeks after treatment, the median $\mathrm{Ct}$-value increases significantly to $34.9(\mathrm{z}=-3.323, P=0.001)$, and was significantly higher than baseline $(\mathrm{z}=-3.137, P=0.002)$. The course of the $\mathrm{Ct}$-values at the different examination time points is shown in Table 4. There was no significant correlation between the $\mathrm{Ct}$ values of the urine-based real-time PCR and the egg counts $(\tau=0.098, P=0.512)$ nor between the serum DNA levels and egg counts $(\tau=-0.032, P=$ 0.812).

\section{Discussion}

In order to prevent egg-induced irreversible pathological reactions, highly sensitive tests for the diagnosis of schistosomiasis are of enormous importance. Hence, an ideal test should identify acute infections, low-intensity infections and residual infections, as well as allow assessment of treatment success and control programs. In this study, the value of detecting cell-free $S$. mansoni DNA in serum and urine was studied as an alternative diagnostic method to detecting eggs in stool or for detecting schistosome antigens in urine. The cell-free circulating schistosome DNA consists of fragments of parasite-derived DNA that is homogeneously distributed in plasma and other body fluids, such as urine or saliva of the host [15, 28-30]. Here, we were able to detect most infections with $S$. mansoni by serum-based real-time PCR (75\%), followed by the POC-CCA test (63.9\%). Comparably few infections were identified with the urine-based real-time PCR method (30.6\%). To determine the diagnostic accuracy, the combined results of microscopy and serumbased real-time PCR were used as reference in this

Table 1 Percentages, mean $(C l)$ and median (minimum, maximum) of positive results for the different diagnostic tests at baseline (pre-treatment) of the 36 study participants

\begin{tabular}{|c|c|c|c|c|c|c|c|}
\hline \multirow[t]{2}{*}{ Method } & \multirow[t]{2}{*}{ Cases/Total } & \multirow[t]{2}{*}{$\%$} & \multicolumn{4}{|c|}{ EPG (Kato-Katz)/ Ct-values real-time PCR } & \multirow[b]{2}{*}{ Maximum } \\
\hline & & & Mean & $\mathrm{Cl}$ & Median & Minimum & \\
\hline Microscopy (Kato-Katz) & $12 / 35$ & 34.3 & 268 & $27.9-508.1$ & 120 & 12 & 1248 \\
\hline POC-CCA & $23 / 36$ & 63.9 & & & & & \\
\hline Serum real-time PCR & $27 / 36$ & 75.0 & 30.4 & $28.8-31.9$ & 30.3 & 22.6 & 38 \\
\hline Urine real-time PCR & $11 / 36$ & 30.6 & 37.7 & $36.3-39.1$ & 38.5 & 33.9 & 40.7 \\
\hline
\end{tabular}

PCR Polymerase chain reaction; EPG Eggs per gram; POC-CCA Point-of-care circulating cathodic antigen; CI Confidence intervals 
Table 2 Sensitivity, NPV with Cl and Kappa statistic of the different diagnostic tests used at baseline. Serum-based real-time PCR and/or Kato-Katz results were used as "gold standard"

\begin{tabular}{llll}
\hline Test method & Sensitivity (95\% Cl) & NPV (95\% Cl $)$ & Kappa $(\boldsymbol{P})$ \\
\hline Microscopy (Kato-Katz) & $44.4 \%(25.5-64.7)$ & $34.8 \%(16.4-57.3)$ & $0.268(P=0.02)$ \\
POC-CCA & $77.8 \%(57.7-91.4)$ & $53.9 \%(25.1-80.8)$ & $0.535(P<0.001)$ \\
Serum-based real-time PCR & $96.3 \%(81.0-99.9)$ & $88.9 \%(51.8-99.7)$ & $0.922(P<0.001)$ \\
Urine-based real-time PCR & $33.3 \%(16.5-54.0)$ & $28 \%(12.2-49.4)$ & $0.119(P=0.25)$ \\
\hline
\end{tabular}

PCR Polymerase chain reaction; POC-CCA Point-of-care circulating cathodic antigen; NPV Negative predicted value; Cl Confidence intervals

study, with both methods being considered $100 \%$ specific. This procedure has also been reviewed and applied in other studies $[27,31]$. The serum-based real-time PCR performed excellently with $96.3 \%$ sensitivity, whereas the urine-based real-time PCR showed the lowest sensitivity (33.3\%) and the lowest Kappa agreement with the "gold standard" (0.119). Various other studies indicate that the diagnosis of $S$. mansoni infection is possible using urine as a source of DNA [32-35]. In our study, the performance of the urine-based real-time PCR was even lower than the KK method, despite the fact that the DNA in the urine was stabilized with a special reagent. Maybe the preservation of DNA was not effective. Promising results were obtained from Lodh et al. with filtered urine samples [36, 37].

In addition, our results showed that the number of positives determined by serum-based real-time PCR was significantly higher 20 weeks after treatment than by parasitological stool examination. Using the KK method, no infection could be detected after treatment, as opposed to $58.3 \%$ with serum-based real-time PCR. There are several explanations for this discrepancy. First, this could be due to low sensitivity of the microscopy (44.4\%) compared to the "gold standard" and could indicate that the eggnegatives were false negative. Second, reinfections with schistosomes are possible in high-transmission areas where humans are exposed to cercaria. The development from the schistosomula to the adult worm, which is capable of laying eggs, takes about 5-7 weeks [2]. In this prepatent period, where no eggs are detectable, schistosome DNA may be detected with the highly sensitive real-time PCR technique. However, since no eggs could be detected microscopically 20 weeks after treatment with PZQ,

Table 3 Prevalences determined using the microscopic KatoKatz method, the POC-CCA rapid diagnostic test and serumbased real-time PCR 20 weeks after therapy with praziquantel

\begin{tabular}{lll}
\hline Method & Cases/Total & $\%$ \\
\hline Microscopy (Kato-Katz) & $0 / 36$ & 0 \\
POC-CCA & $12 / 36$ & 33.3 \\
Serum real-time PCR & $21 / 36$ & 58.3 \\
\hline
\end{tabular}

this indicates a rather slow dynamic of reinfection at this transmission site. Third, some authors point out that the effectiveness of praziquantel for the treatment of schistosomiasis is not as effective as previously thought, or that resistance may develop [28, 38-40]. This may indicate that real-time PCR can be a useful tool for evaluating treatment success. The last two mentioned aspects would also explain the 33.3\% positive POC-CCA test results in our study. Lamberton et al. demonstrated in their drug efficacy study 2014, that the POC-CCA test was more sensitive than six KK slides at 4 weeks after PZQ treatment, and again at 6 months after chemotherapy [41].

In the current study, we were able to detect changes in the $\mathrm{Ct}$ value after treatment with PZQ and thus draw conclusions about changes of the amount of free circulating S. mansoni DNA. The free DNA presumably originates from the adult worms killed by the therapy [19], which leads to a significant increase in the DNA concentration in the hosts body (1 week post-treatment median $\mathrm{Ct}$ was 28). This was followed by an increase in the $\mathrm{Ct}$ value at the second follow-up examination (20 weeks after treatment median Ct was 34.9), which, was higher than at baseline (median Ct 30.3). Similar results have been reported in other studies [19, 42]. Since people with chronic infections have a large number of eggs in their tissues and DNA is probably released at very slow kinetics, free-circulating DNA may be detected several months after therapy [30, 43]. Nevertheless, studies on the detection of $S$. japonicum by classical PCR showed that the DNA of this parasite was no longer detectable 6-8 weeks after treatment with praziquantel [44]. It is also possible that the circulating DNA detected in this study, 20 weeks after treatment with praziquantel, is due to reinfection. Like many other studies, we have found no correlation between the $\mathrm{Ct}$ value and the number of eggs in the stool samples $[45,46]$. One possible explanation for this is that the real-time PCR method used to detect $S$. mansoni-specific DNA is able to detect it from all stages of the life cycle. A positive PCR reaction shows that DNA of the parasite is present but not whether it comes from egg-producing worm pairs or, for example, larval stages [46]. 
Table 4 Proportion, mean $(C l)$ and median (minimum, maximum) of positive results of the serum-based real-time PCR at the various examination time points

\begin{tabular}{llll}
\hline Serum real-time PCR & Pre-treatment & Post-treatment 1 & Post-treatment 2 \\
\hline & & $(1$ week) & $(20$ weeks) \\
\% positives & $27(75)$ & $27(75)$ & $21(58.3)$ \\
Mean Ct-value $(C)$ & $30.4(28.8-31.9)$ & $28.4(27.1-29.7)$ & $33.9(32.2-35.5)$ \\
Median Ct-value (min, max) & $30.3(22.6,38)$ & $28(21.5,35.9)$ & $34.9(26.6,38.6)$ \\
\hline
\end{tabular}

$C I$ Confidence intervals; $P C R$ Polymerase chain reaction; $C t$ Cycle threshold

\section{Conclusions}

Despite the fact that the results of the current study are based on a very small sample size and this may have affected the results, we conclude that serum-based realtime PCR has an added value in a variety of situations. Although it cannot replace the KK method or the POCCCA test in endemic areas, this method is well suited to detect schistosomiasis very early or infections with low intensities, because of its high diagnostic accuracy. This is particularly useful for travelers and migrants to prevent possible chronic complications of an unrecognized disease or for long-term monitoring of control interventions. However, as circulating DNA does not necessarily reflect the persistence of living worms in schistosomiasis, this method is less well suited to verify the success of treatment with praziquantel.

\section{Supplementary information}

Supplementary information accompanies this paper at https://doi.org/10. 1186/s40249-020-00698-z.

Additional file 1. Dataset

\section{Abbreviations}

CCA: Circulating cathodic antigen; Cl: Confidence intervals; Ct: Cycle threshold; KK: Kato-Katz; LAMP: Loop-mediated isothermal amplification; MDA: Mass drug administration; NIMR: National Institute for Medical Research; NPV: Negative predicted value; PCR: Polymerase chain reaction; POC-CCA: Point-of-care circulating cathodic antigen; PZQ: Praziquantel

\section{Acknowledgements}

We gratefully acknowledge the technicians of the National Institute for Medical Research, Mwanza, who were involved in sample collection and microscopic analysis. They also assisted in drug administration and helped with the collection of information and data necessary for this study. We would also like to thank the study participants for their cooperation.

\section{Authors' contributions}

AF and AM conceived and conducted the experiment(s). AF and HDM analysed the results. AF wrote the draft manuscript. All authors read and approved the final manuscript.

\section{Funding}

This study was funded by the Georg Ludwig Rexroth Foundation (http:// www.rexroth-stiftung.de) and German Academic Exchange Service (Deutscher Akademischer Austauschdienst, DAAD grant number 57141273 (https://www.daad.de/de/)). The funders had no role in study design, data collection and analysis, decision to publish, or preparation of the manuscript.

Availability of data and materials

All relevant data are within the paper and its Supporting Information files.
Ethics approval and consent to participate

Written informed consent was obtained from all participants. This project was reviewed and specifically approved by the Catholic University of Health and Allied Sciences (CUHAS), Ethics Review Board, Mwanza, Tanzania (Research Clearance Certificate No CREC/243/2017) and by the National Institute for Medical Research (Research Clearance Certificate No NIMR/HQ/ R.8a/Nol.IX/2679). Participants who were positive by microscopic examination or POC-CCA test cassette for S. mansoni were treated with PZQ using the $\mathrm{WHO}$ recommended clinical dosage (40 $\mathrm{mg} / \mathrm{kg}$ body weight).

\section{Consent for publication}

Not applicable.

\section{Competing interests}

The authors declare that they have no competing interests.

\section{Author details}

${ }^{1}$ Medical Mission Institute, Hermann-Schell-Str. 7, 97074 Wuerzburg, Germany. ${ }^{2}$ School of Medicine, Department of Medical Parasitology \& Entomology, Catholic University of Health and Allied Sciences, P.O. Box 1464, Mwanza, Tanzania. ${ }^{3}$ Klinikum Wuerzburg Mitte gGmbH, Medical Mission Hospital, Dept. of Tropical Medicine, Wuerzburg, Germany.

Received: 9 March 2020 Accepted: 11 June 2020

Published online: 22 June 2020

\section{References}

1. $\mathrm{WHO}$ | Schistosomiasis and soil-transmitted helminthiases: numbers of people treated in 2018. Weekly Epidemiological Record, 13 December 2019, vol. 94, 50 (pp. 601-612) [Internet]. WHO. World Health Organization; [cited 2020 Apr 20]. Available from: http://www.who.int/wer/2019/wer9450/en/.

2. Colley DG, Bustinduy AL, Secor WE, King CH. Human schistosomiasis. Lancet Lond Engl. 2014 Jun 28;383(9936):2253-64.

3. Utzinger J, Raso G, Brooker S, De Savigny D, Tanner M, Ørnbjerg N, et al. Schistosomiasis and neglected tropical diseases: towards integrated and sustainable control and a word of caution. Parasitology. 2009 Nov;136(13): 1859

4. Ajibola O, Gulumbe BH, Eze AA, Obishakin E. Tools for Detection of Schistosomiasis in Resource Limited Settings. Med Sci [Internet]. 2018 May 23 [cited 2020 Apr 20];6(2). Available from: https://www.ncbi.nlm.nih.gov/ pmc/articles/PMC6024580/.

5. Bärenbold O, Raso G, Coulibaly JT, N'Goran EK, Utzinger J, Vounatsou P. Estimating sensitivity of the Kato-Katz technique for the diagnosis of Schistosoma mansoni and hookworm in relation to infection intensity. PLoS Negl Trop Dis. 2017 Oct:11(10):e0005953.

6. Silva Filho JD. da, Pinheiro MCC, Sousa MS, Gomes V da S, Castro IMN de, Ramos Júnior AN, et al. detection of schistosomiasis in an area directly affected by the São Francisco River large-scale water transposition project in the northeast of Brazil. Rev Soc Bras Med Trop. 2017;50(5):658-65.

7. Standley C, Lwambo N, Lange C, Kariuki H, Adriko M, Stothard J. Performance of circulating cathodic antigen (CCA) urine-dipsticks for rapid detection of intestinal schistosomiasis in schoolchildren from shoreline communities of Lake Victoria. Parasit Vectors. 2010;3:7.

8. Adriko M, Standley CJ, Tinkitina B, Tukahebwa EM, Fenwick A, Fleming FM, et al. Evaluation of circulating cathodic antigen (CCA) urine-cassette assay as a survey tool for Schistosoma mansoni in different transmission settings within Bugiri District, Uganda. Acta Trop. 2014;136:50-7. 
9. Bezerra FSM, Leal JKF, Sousa MS, Pinheiro MCC, Ramos AN, Silva-Moraes V, et al. Evaluating a point-of-care circulating cathodic antigen test (POC-CCA) to detect Schistosoma mansoni infections in a low endemic area in NorthEastern Brazil. Acta Trop. 2018 Jun 1;182:264-70.

10. Kato-Hayashi N, Leonardo LR, Arevalo NL. Tagum MaNB, Apin J, Agsolid LM, et al. detection of active schistosome infection by cell-free circulating DNA of Schistosoma japonicum in highly endemic areas in Sorsogon Province, the Philippines. Acta Trop. 2015 Jan 1;141:178-83.

11. Shiff C. Accurate diagnostics for schistosomiasis: a new role for PCR? [Internet]. Reports in Parasitology. 2015 [cited 2016 Dec 9]. Available from: https://www.dovepress.com/accurate-diagnostics-for-schistosomiasis-a-newrole-for-pcr-peer-reviewed-fulltext-article-RIP

12. Cavalcanti MG, Silva LF, Peralta RHS, Barreto MGM, Peralta JM. Schistosomiasis in areas of low endemicity: a new era in diagnosis. Trends Parasitol. 2013 Feb 1;29(2):75-82.

13. Kincaid-Smith J, Rey O, Toulza E, Berry A, Boissier J. Emerging Schistosomiasis in Europe: a need to quantify the risks. Trends Parasitol. 2017;33(8):600-9.

14. Wong SS, Fung KS, Chau S, Poon RW, Wong SC, Yuen K-Y. Molecular diagnosis in clinical parasitology: when and why? Exp Biol Med. 2014 Nov 1; 239(11):1443-60.

15. Pontes LA, Dias-Neto E, Rabello A. Detection by polymerase chain reaction of Schistosoma mansoni DNA in human serum and feces. Am J Trop Med Hyg. 2002 Jan 2;66(2):157-62.

16. Espírito-Santo MCC, Alvarado-Mora MV, Pinto PLS, de Brito T, Botelho-Lima L, Heath AR, et al. Detection of Schistosoma mansoni infection by TaqMan ${ }^{\circledast}$ RealTime PCR in a hamster model. Exp Parasitol. 2014;143(Supplement C):83-9.

17. Abbasi I, King CH, Muchiri EM, Hamburger J. Detection of Schistosoma mansoni and Schistosoma haematobium DNA by loop-mediated isothermal amplification: identification of infected snails from early Prepatency. Am J Trop Med Hyg. 2010 Aug 5;83(2):427-32.

18. Hamburger J, Turetski T, Kapeller I, Deresiewicz R. Highly repeated short DNA sequences in the genome of Schistosoma mansoni recognized by a species-specific probe. Mol Biochem Parasitol. 1991 Jan 1;44(1):73-80.

19. Wichmann D, Panning M, Quack T, Kramme S, Burchard G-D, Grevelding C, et al. Diagnosing Schistosomiasis by Detection of Cell-Free Parasite DNA in Human Plasma. PLoS Negl Trop Dis [Internet]. 2009 Apr 21 [cited 2016 Dec 13]; 3(4). Available from: http://www.ncbi.n/m.nih.gov/pmc/articles/PMC2667260/.

20. Gomes AL. Do V, Melo FL, Werkhauser RP, Abath FG. Development of a real time polymerase chain reaction for quantitation of Schistosoma mansoni DNA. Mem Inst Oswaldo Cruz. 2006 Oct;101:133-6.

21. Mazigo HD, Dunne DW, Wilson S, Kinung'hi SM, de Moira AP, Jones FM, et al. Co-infection with Schistosoma mansoni and Human Immunodeficiency Virus-1 (HIV-1) among residents of fishing villages of north-western Tanzania. Parasit Vectors [Internet]. 2014 Dec 16 [cited 2017 Aug 16];7. Available from: http://www.ncbi.n/m.nih.gov/pmc/articles/PMC4271490/.

22. Mazigo HD, Dunne DW, Morona D, Lutufyo TE, Kinung'hi SM, Kaatano G, et al. Periportal fibrosis, liver and spleen sizes among S. mansoni mono or co-infected individuals with human immunodeficiency virus-1 in fishing villages along Lake Victoria shores, North-Western, Tanzania. Parasit Vectors [Internet]. 2015 May 7 [cited 2016 Aug 17]; 8. Available from: http://www. ncbi.nlm.nih.gov/pmc/articles/PMC4424565/.

23. Malenganisho WLM, Magnussen P, Friis H, Siza J, Kaatano G, Temu M, et al. Schistosoma mansoni morbidity among adults in two villages along Lake Victoria shores in Mwanza District, Tanzania. Trans R Soc Trop Med Hyg. 2008 Jun;102(6):532-41.

24. Kardorff R, Gabone RM, Mugashe C, Obiga D, Ramarokoto CE, Mahlert C, et al. Schistosoma mansoni-related morbidity on Ukerewe Island, Tanzania: clinical, ultrasonographical and biochemical parameters. Trop Med Int Health TM IH. 1997 Mar;2(3):230-9.

25. $\mathrm{WHO} \mid$ Basic laboratory methods in medical parasitology (archived) [Internet]. WHO. [cited 2017 Aug 28]. Available from: http://www.who.int/ malaria/publications/atoz/9241544104_part1/en/.

26. Katz N, Chaves A, Pellegrino J. A simple device for quantitative stool thicksmear technique in Schistosomiasis mansoni. Rev Inst Med Trop Sao Paulo. 1972 Dec;14(6):397-400.

27. Vinkeles Melchers NVS, van Dam GJ, Shaproski D, Kahama Al, Brienen EAT, Vennervald BJ, et al. Diagnostic Performance of Schistosoma Real-Time PCR in Urine Samples from Kenyan Children Infected with Schistosoma haematobium: Day-to-day Variation and Follow-up after Praziquantel
Treatment. PLoS Negl Trop Dis [Internet]. 2014 Apr 17 [cited 2019 Jun 25];8(4). Available from: https:/www.ncbi.nlm.nih.gov/pmc/articles/PMC3990496/.

28. Mwinzi PNM, Kittur N, Ochola E, Cooper PJ, Campbell CH, King CH, et al. Additional Evaluation of the Point-of-Contact Circulating Cathodic Antigen Assay for Schistosoma mansoni Infection. Front Public Health [Internet]. 2015 Mar 19 [cited 2017 Sep 13];3. Available from: http://www.ncbi.nlm.nih.gov/ pmc/articles/PMC4365547/.

29. Weerakoon KG, Gordon CA, McManus DP. DNA diagnostics for Schistosomiasis control. Trop Med Infect Dis. 2018;3(3):81.

30. Kato-Hayashi N, Yasuda M, Yuasa J, Isaka S, Haruki K, Ohmae H, et al. Use of cell-free circulating Schistosome DNA in serum, urine, semen, and saliva to monitor a case of refractory imported Schistosomiasis Hematobia. J Clin Microbiol. 2013 Oct;51(10):3435-8.

31. Coulibaly JT, N'Gbesso YK, Knopp S, N'Guessan NA, Silué KD, van Dam GJ, et al. Accuracy of Urine Circulating Cathodic Antigen Test for the Diagnosis of Schistosoma mansoni in Preschool-Aged Children before and after Treatment. Liang S, editor. PLoS Negl Trop Dis. 2013;7(3):e2109.

32. Fernández-Soto $P$, Gandasegui J, Rodríguez CC, Pérez-Arellano JL, CregoVicente B, Diego JG-B, et al. Detection of Schistosoma mansoni-derived DNA in human urine samples by loop-mediated isothermal amplification (LAMP). PLoS One. 2019 Mar 26;14(3):e0214125.

33. Mj E, Silva Go E, Rodrigues NB. Diagnostic Accuracy and Applicability of a PCR System for the Detection of Schistosoma mansoni DNA in Human Urine Samples from an Endemic Area. PLOS ONE. 2012;7(6):e38947.

34. Mj E, Oliveira Silva GE, Rodrigues NB. A salting out and resin procedure for extracting Schistosoma mansoni DNA from human urine samples. BMC Res Notes. 2010;3(1):115

35. Weerakoon KG, Gordon CA, Williams GM, Cai P, Gobert GN, Olveda RM, et al. Droplet digital PCR diagnosis of human Schistosomiasis: parasite cellfree DNA detection in diverse clinical samples. J Infect Dis. 2017 Dec 19; 216(12):1611-22

36. Lodh N, Mwansa JCL, Mutengo MM, Shiff CJ. Diagnosis of Schistosoma mansoni without the stool: comparison of three diagnostic tests to detect Schistosoma [corrected] mansoni infection from filtered urine in Zambia. Am J Trop Med Hyg. 2013 Jul;89(1):46-50.

37. Lodh N, Naples JM, Bosompem KM, Quartey J, Shiff CJ. Detection of ParasiteSpecific DNA in Urine Sediment Obtained by Filtration Differentiates between Single and Mixed Infections of Schistosoma mansoni and S. haematobium from Endemic Areas in Ghana. PLOS ONE. 2014:9(3):e91144.

38. Wang W, Wang $L$, Liang Y-S. Susceptibility or resistance of praziquantel in human schistosomiasis: a review. Parasitol Res. 2012 Nov 1;111(5):1871-7.

39. Doenhoff MJ, Cioli D, Utzinger J. Praziquantel: mechanisms of action, resistance and new derivatives for schistosomiasis. Curr Opin Infect Dis. 2008 Dec:21(6):659-67.

40. Doenhoff MJ, Kusel JR, Coles GC, Cioli D. Resistance of Schistosoma mansoni to praziquantel: is there a problem? Trans R Soc Trop Med Hyg. 2002 Oct;96(5):465-9.

41. Lamberton PHL, Kabatereine NB, Oguttu DW, Fenwick A, Webster JP. Sensitivity and specificity of multiple Kato-Katz thick smears and a circulating Cathodic antigen test for Schistosoma mansoni diagnosis pre- and post-repeatedPraziquantel treatment. PLoS Negl Trop Dis. 2014 Sep 11;8(9):e3139.

42. Eraky MA, Aly NSM. Diagnostic and prognostic value of cell free circulating Schistosoma mansoni DNA: an experimental study. J Parasit Dis Off Organ Indian Soc Parasitol. 2016 Sep;40(3):1014-20.

43. Wichmann D, Poppert S, Von Thien H, Clerinx J, Dieckmann S, Jensenius M, et al. Prospective European-wide multicentre study on a blood based real-time PCR for the diagnosis of acute schistosomiasis. BMC Infect Dis. 2013;13:55.

44. Wang C, Chen L, Yin X, Hua W, Hou M, Ji M, et al. Application of DNA-based diagnostics in detection of schistosomal DNA in early infection and after drug treatment. Parasit Vectors. 2011 Aug 24;4:164

45. Espírito-Santo MCC, Alvarado-Mora MV, Dias-Neto E, Botelho-Lima LS, Moreira JP, Amorim M, et al. Evaluation of real-time PCR assay to detect Schistosoma mansoni infections in a low endemic setting. BMC Infect Dis. 2014 Oct 23:14:558.

46. Cnops L, Tannich E, Polman K, Clerinx J, Van Esbroeck M. Schistosoma realtime PCR as diagnostic tool for international travellers and migrants: Schistosoma real-time PCR as diagnostic tool. Tropical Med Int Health. 2012 Oct:17(10):1208-16. 